\title{
Confinement, community, citizenship
}

\author{
Deborah Espiner ${ }^{1}$ and Frances Hartnett ${ }^{2}$
}

\begin{abstract}
This article applies the social model of disability (Oliver 1996) and the theory of social role valorisation (Wolfensberger 1998a) to the life experiences as told in the words of a man who experienced being institutionalised at 17 years of age. A focussed conversation (Stanfield 2000) was used to support the man to retell some of the challenges, achievements and satisfactions he wished to share. This story outlines how he utilised his experiences to transform his life and advocate for people with learning disabilities to be treated fairly. Today he is a member on a number of Boards, striving to ensure that people with learning disabilities receive the service and support they desire.
\end{abstract}

Keywords: learning disability; disability theory; story telling; advocacy

1. Principal Lecturer, School of Counselling, Human Services and Social Work, University of Auckland 2. Service Advisor, Northern Region IDEA Services

Address for correspondence: Deborah Espiner, School of Counselling, Human Services and Social Work, Faculty of Education, University of Auckland, PO Box 92601 Symonds Stree, Auckland, New Zealand.d.espiner@auckland.ac.nz 
When there are walls of ignorance between people, when we don't know each other's stories, we substitute our own myth about who that person is. When we are operating with only a myth, none of that person's truth will ever be known to us, and we will injure them - mostly without ever meaning to. (Wehmiller 1992, p.380).

\section{Introduction}

People with intellectual disability are at greater risk of exposure to a range of adversities than their non-disabled peers (Broberg et al 2009). Wolfensberger (1998a) postulates that a person with differences that are negatively perceived by society (such as having an intellectual disability or living on the streets), is at high risk of devaluation, adversity and poor treatment by the majority in that society. According to Wolfensberger when people are devalued they are at heightened risk of being subjected to a 'wounding process' described as 'the bad things that typically get done to devalued people' (Wolfensberger 1998a, p.12). Devaluation expresses itself at individual and collective levels in the form of assumptions (Wolfensberger 1998 a) that can generate actions that result in specific service models, policies and cultures. These actions are most likely to be detrimental to the interests and quality of life of the individual/s concerned (Schein, 2010). Furthermore, the "common assets' (Wolfensberger 1988b) that people with intellectual disabilities have, can be lessened through degrading life circumstances inhibiting positive development and growth.

The individual model (Oliver 1996) portrays disability as an individual problem with difficulties and challenges arising as a direct result of the person's impairment. This gives rise to a 'deficit' and 'fix it up' focus highlighting there is something 'wrong' with the person. Disability theory has evolved from a deficit focus to a model focussing on people's capacities and strengths. The social model sees disability not as an individual problem but as a social issue where 'people are disabled by society's reaction to impairment which prevents their participation as equal citizens' (Inclusion Scotland 2005, p. 3). A third model, the affirmative model, has a 'non-tragic' view of disability and impairment promoting a more positive way of perceiving disabled people. This model focuses on 'positive social identities, ... grounded in the benefits of life style and life experience of being impaired and disabled' (Swain and French 2000, p. 569). The affirmative model, while acknowledging disability, celebrates 'self' and identity 'I am what I am' (p. 576). Swain and French (2008) state that 'many disabled people have taken the position that disability is both identity and pride, through the celebration of difference' (p. 2) expressing itself through resilience and resistance to the tragedy view of disability.

A strength based approach contrasts with a deficit based approach that focuses on the elimination of factors that cause dismay and failure. Sheldon and King (2001) 
assert that functioning cannot be understood only from a 'negative' or 'problem focused frame of reference' (p. 261). They advocate that a more positive outlook uncovers a deeper understanding of the ways in which people adapt to stressful situations and thrive. Lemay (2005) proposes that experiencing 'a typical or indeed valued life might overcome much past adversity' (p. 2) for disabled people. In a similar way, Masten (2001) highlights the 'ordinary magic' (p. 238) of everyday lives and experiences and living the magic of an ordinary life will support people to expand their resiliency capacity (Leadbeater et al 2005) as new skills, knowledge and challenges emerge. While most of the resilience research has focused on youth, resilience can develop throughout adulthood (Werner and Smith 2001). Research on resilience has also focused on typical development and/or on youth who are considered to be at risk (Luthar and Brown 2007; Ungar 2008). It is only recently that the study of resilience in relation to people with disabilities has become more topical (Broberg et al 2009).

Storytelling promotes development of personal resilience and recognition and celebration of the hardiness of individuals who contribute to knowledge through retelling how they overcame adversity (East et al 2010). The following story is an important one, as despite adversity and devaluation, this man developed hardiness through meeting challenges, problem solving, finding purpose, contribution and contentment. The story is an account of a transformative journey from confinement, to community, to citizenship.

\section{Methodology}

The storyteller approached the writers when he realized he had an important story to tell. He wished to share his story to highlight some of the challenges, achievements and satisfactions he had experienced throughout his life. The storyteller asked the writers to use his Christian name (Kevin) in the telling of his story and the writing of the article. There was a long-standing relationship between Kevin and the writers and trust and respect was reciprocal and well developed. East et al (2009), highlight the importance of an atmosphere of acceptance to enhance the safety and comfort of the storyteller and the resulting scope of the story.

Initially, Kevin presented his story at a conference where a number of selfadvocates, human and social service personnel and government representatives would be present. He sought the support of the writers in preparing for and delivering his presentation. The presentation was well received and was a satisfying and clarifying experience. Recounting life stories has been reported to be empowering and clarifying (Meininger 2006). Furthermore, telling life stories enriches understanding of experiences and promoting a deeper sense of self (Atkinson 2004). The impact of the conference presentation and the interest generated led to Kevin's wish to have a 
more permanent record of his story. As a strong advocate for people with disabilities and other marginalised groups, Kevin believed that his experiences could provide valuable insights into past treatment of people with disabilities and ways in which support could be delivered in more equitable ways (Roberts and Hamilton 2010).

Information was gained through a focused conversation (Stanfield 2000). This was considered an effective approach in supporting Kevin to sift, sort and summarise ideas. It was anticipated that the conversation could be an emotional and reflective time for him. The four-level framework of questions (Stanfield 2000) was seen potentially as a major support in moving the conversation forward at a pace that was comfortable and satisfying to him. The four levels, comprising objective (facts and realities); reflective (personal response); interpretative (personal significance and meaning); and decisional (resolution and future plans) questions was considered to be an effective conversation guide.

Kevin told his story to the writers on six occasions, and each occasion was audiotaped. The audiotapes enabled him to reflect on the content and to add further detail and/or make changes to what he had said. As each draft of the article was written the content was read to Kevin and modifications made at his request. Ethical approval was awarded from the Ethics Committee, University of Auckland, New Zealand and the completed article had Kevin's approval. While Kevin wanted his name to appear in the article anonymity of places and people associated with the story has been preserved. The use of James K Baxter's name and the name of the commune are exceptions. James K Baxter is recognized as one of New Zealand's foremost poets and his life is fully documented as is the history of the Jerusalem settlement on the Wanganui River (Newton 2009).

Kevin suggested and willingly gave access to the writers to review supporting information. Audio-recordings from the Confidential Listening Service, hospital records and excerpts from a book (Newton 2009) validated his story as told to the writers. It is acknowledged that stories are subjective, vary over time and that human memory is fallible (Kitzinger 2004). However stories do hold value in contributing towards an understanding of challenging life events thus deepening personal awareness and identity (Atkinson 2005).

\section{Kevin's story in his words}

At school I went to [Name] Primary School, then mum and dad moved to Wellington. I was all over the place. I went to schools all over the blimmin' place - it didn't give me the chance to learn properly. Then what school, I went to [Name] School and then to another school where I was just made clean out rubbish bins 'cos I could not get the jiff of things. Dad and mum moved again and the teacher picked up I couldn't read or 
write properly but it was too late so dad pulled me out of school and I started working with him the bakery. I left school when John F Kennedy was assassinated, when I was 15.

Between school and [Name] Hospital I was working with my dad. My dad did a lot of casual work and I was doing casual work with him. One of the first jobs was Sexton in the cemetery, then the freezing works. I worked with my father, he took me, it was like casual work and I enjoyed doing it. My dad lost his job and then I couldn't get one - I lived on the street, I enjoyed it.

\section{Shoved into a mental hospital}

In 1968 I was accused of doing something wrong, pinching a pair of shoes that I had not done. I thought I would be locked up for one year instead of that they stuck me in [Name] Hospital and I wasn't told I was going there. It was the judge - the justice system decided I was feebleminded. I thought I was going to jail but I went to a mental hospital. I wasn't told I was going there. In those days they could do many things to you but today they can't. People have been saying you can go them 'cos justice has been taken away from me and shoved into a mental hospital at that age. I am going to follow that up, I want something done about it.

I was there for four years in total. It was pretty horrible, pretty nasty there the way people were treated. There was a lot of blaming and finger pointing. They treated me like dirt - if you stepped out of line you were shoved into a room and told you shouldn't have this, you shouldn't have done that. I fell from a tree and injured myself and they didn't even bother caring about me - even though they were a hospital, that's what they were like. You were put to work in the laundry, cleaning, in the gardens. They were boring jobs. I got 7 shillings a week and then when the currency changed I got $\$ 15$ a week for all that work you done - and it was like from Monday to Friday. I also got a small packet of tobacco weekly. I saw shock treatment and was put in the rooms to clean up the mess after the poor buggers were given a shock. You know, you had to go and make the beds and someone else would come and get shocked and you would do it all again.

Some of the things that happened to me I felt shouldn't have been done to me and I was lucky I wasn't shocked. They wanted to do to me was to send me up to another hospital out there, about two hours' drive away but my mother stepped in and said 'no he is not going out there'.

You got labels like 'he's a mug, he can't read or write properly'... so I got treated like dirt out there and a lot of nurses did treat me like dirt. 
There were some people who treated you OK. A friend of my mine and my mother's used to work at the bakery - he come in as a nurse and he was like family so he kept an eye on me - he showed me respect - some of the other staff don't. You know you get good staff and you get bad staff so then on I thought I will trust this guy and I won't trust anybody else. [Name] the gardener was a really nice guy.

I was 17 when I went to [Name] Hospital, I was 22 getting out ...it was a long time of my life. I did not know why I was there. They had a name for it - feeble minded that's all - feeble minded. I went there - just 'cos I was feeble-minded. I got the labels once in hospital. I don't trust anyone any more.

While I was at the hospital mum and dad, they would get me up for the weekends. I have a brother living in Australia way out from Sydney too far to come and see me and the other brother passed away - he has been gone 10 or 12 years now. He was the closest one to me 'cos when I was in hospital on the weekends he would take me walking, he used to come and walk with me.

I first spent two years in there, [Name] Hospital and was let out - but when you have been in a place like that you can't handle yourself so I readmitted myself. You can't handle the world so I went back inside voluntarily. It took a long process to get over things.... as the way they treated you was shocking.

\section{Somewhere else to be}

When I came out of [Name] Hospital at 22 I went fruit picking in Nelson. I met this guy on the ferry and he said come and stay with me, there is a chap on the Wanganui River at Jerusalem called James K Baxter up the Wanganui River. There are people there who have pulled themselves out of the gutter. I wanted to be part of a community so I headed up there I wanted somewhere else to be - to be connected and part of something. The next day I got the train and hitched, I got picked up by a petrol tanker and taken through to Wanganui.

Jerusalem is a commune. When I arrived there was a guy coming up the track in a dinner jacket and I thought what is going on here. One of the ladies I still see around, I remember, I was arriving and she was on the way out and she asked me for a safety pin and I said 'Sorry lady'... a safety pin but I still see her a lot around town.

Hemi [Maori name for James K. Baxter] was a great guy, he was a great guy, he wrote a lot of stories and he took me lecturing with him. Top House was where people come and stayed, some passed through, 
and some stayed there. There was lots of different people, lot of people popped in, different generations. It depended on the day how many were there, some people just wanted to see what it was like, others stayed on. One Easter we had about 100 people come in, the house was over full. We got used to a whole lot of people, some people bought food but I kept it possum free so the possums didn't eat the vegetables and fruit. We used the meat for food and the skins for hats.

At the commune a lot of the guys didn't realise I had been in a mental hospital but I would break down and cry or cower in the corner and then I said 'sorry guys I had a problem I couldn't deal with' and they understood. Jerusalem was like a family, it is a nice place.

A typical day I would pluck geese, I did a lot of hunting, I went out and got fresh meat I would hunt a goat. I was helping around the place, I was a general dogsbody. Some of the meat went up to the marae and some went up to the Top House so there was fresh food available. I hunted, built, cleaned up the cemeteries, the garden went in, kept the possums out of there, I did a lot of work. I did docking sheep, I was asked to help with the sheep, cutting their tails, I did a lot of work around the place, I was the only one, no one else wanted to do it so I put my hand up for it. [Name commune member] and me didn't want any power on so we took a bow saw to the power pole - but it didn't fall over. It is still standing today with a chunk out. We didn't want the power 'cos we got used to having no power, Hemi took us to task 'cos he wanted the power. The pole is still standing, it is amazing.

There were some nuns living near the commune and they found out I had a problem reading and writing and they taught me enough to get by on. This was the first time I had been taught to read I slipped through the cracks at school. This paid off.

There is book The Double Rainbow about Jerusalem, a guy called John did it, and I went back to help sort through the photos of what would go in the book.

I still see some people, and some others.

There was a sad moment in 1972, it was a horrid year as Hemi passed away, poor Hemi. I was staying in Auckland and I was the last person to see him alive. I would leave the commune sometimes to make money for the commune. I was up in Auckland working in [Name of suburb] keeping the grounds tidy and that so I had to race back. I was a pall-bearer, not many people were asked to carry him there was only a handful of people- people that were close to him and were chosen to carry him. We carried Hemi up the hill, hand chosen by the elders, no one else was allowed to go near him - it was a privilege. They respected the people there, I got respect there. 
Hemi was good, he was a real nice guy and I know he took me under his wing. He would take me with him lecturing which is amazing, no one else, he wouldn't take anyone else. I was so amazed to go with him. He was lovely I knew his family, his son and his daughter. I spoke to them last year, I am lucky to know his family. A lot of people didn't like him because he started the community but after he passed a lot of people started to like him. I took him home and mum nearly freaked out 'cos he was a scruffy old guy.

There were no drugs, no allowed drugs he would not toleration drugs, the elders would kick you out and you would not be able to come back. A guy did, they threw him out and he was banned for life - they threw him out... The drug squad always harassed us guys and people used to freak out so [Name community member] took them on, asked to see the head head guy in Auckland - we spoke to him and said you have to come and meet the people and he actually fronted up. This is taking the bull by the horns and doing as she did she didn't muck about - they were harassing and frightening I would break down 'cos I was terrified. After they met us they left us alone.

Hemi's love of poetry inspired me to write a poem. There was cave near the commune I wrote about it. It had a water slide and glow worms you could see them.

\author{
Glow Worm Cave \\ The cave I didn't know existed \\ A figment of my imagination \\ Slip in the cave \\ Glow, glow cave \\ A special place to be \\ An amazing waterslide.
}

After Hemi died I stayed as it was so peaceful and I loved the hills and I did a lot of work. However it was not the same place without Hemi but it was very interesting as the commune broke up 'cos he kept it together. Things changed. After Hemi passed a lot of people went up to Reef Point and I decided to live up there. Reef Point was another commune with the same group of people. How we survived was getting crayfish, paua fish (the right size) and went to the Freezing Works and got money that way, selling it at Freezing Works. Seaweed was sold by the bale and we also dug up kauri gum and sold that. That is how we got our money. Reef Point was not the same so I decided to leave. 


\section{Getting out into the neighbourhood and going for it}

After then I went to Wellington and lived with people from Jerusalem. I worked in New Zealand Railway in Wellington for 10 years. I worked from 2 o'clock in the morning till 4 o'clock in the afternoon. I started off as a cleaner then the new boss recognised what I was good at so he took me off cleaner and started me on stowing and unloading wagons. I looked after the livestock as well and load the train.

After Wellington I come up to Auckland I actually transferred up here. I heard about redundancy so I moved to Auckland and moved to Navy. I was three years there and had to sign a confidential form.

There's a Confidential Listening Service they got in touch with methey are people in Wellington, part of the government, one was a judge and two other people and they recorded a CD of what happened to me. So I invited [Name of advocate] to come along with me. I asked for all my notes and they got the whole for me, so I was really grateful. Before then I had asked the Health Board for my notes but instead of getting the whole lot they held back a lot but the Confidential Listening Service they got the lot for me. I was having nightmares of going back into the hospital from being locked up so what they did for me was get me a counsellor which was great it helped me get over things. Confidential Listening Service gives free counselling. I hope they get an apology for how they treated people with disabilities - they still get treated bad. A letter of apology would be good, it would be nice for us.

I volunteer for [Name of Trust], it is for people with mental illness and we plant trees. Every Wednesday we clear streams and plant trees. I have been doing this for 2 years. We have started a new group it's called Action Council. If people have problems we give advice and tell them how to handle it. I'm also on the Health and Safety Committee.

l've been involved with Citizen Advocacy for 22 years. If someone needs an advocate we try and find them one and match them up. I wanted an advocate and that is how I got in. [Name] is my advocate I have known her and her kids and her family for 23 years, she is like a big sister. l've been on the Board for 23 years, l'm not giving it up.

At [Name of Trust] I was Core Person for 2 years, I was on the Trust of the Board. In 2011 someone did something unrespectable to me, got hold of my files from [Name] Hospital and tried to hold what was in hospital against me. He tried to roll me from the Board so he could get power over me. I stood fast and the lawyers told him he couldn't do that you have no right to do that to Mr Rogers and that was only a year ago. It was shocking they shouldn't do that.

I do a lot of community projects. I do the Santa Parade. I also do the 
Big Event and Seafood Festival. This is me today getting out into the neighbourhood and going for it.

\section{One of my hopes}

One of my hopes is if someone is working they should be working alongside the boss so they can get to know them. People with disabilities should be in parliament working with people, people working together and alongside and where do we go from here. I am getting on but I still like to fight for people's rights or be on the Council making sure things are done properly.

People with disabilities don't get a fair deal - there should be someone they can go to to say look I have this thing done, someone is treating me unfairly. I am not being treated fairly. If they cannot go to the Human Rights Commission they should have somewhere to go to be able to go to say look I need help.

\section{What Kevin's story tells us: A commentary}

Kevin's story is a powerful illustration of the theory of social role valorisation (Wolfensberger 1998a) and the social model of disability (Oliver 1996). These two theories have been foundational in deepening understanding of the experience of disability and have influenced societal attitudes and resulting service provision and support.

Kevin's story illustrates how, in the 1960 - 1970's in New Zealand, in common with the United States and the United Kingdom, a person with a learning disability could be institutionalised within a psychiatric hospital for a minor one-off criminal offence. Frequently this placement resulted in a longer stay in a restrictive environment than would have placement within the criminal justice system. Psychopaedic (mind of a child) hospitals were a feature of the health system in 1970's New Zealand. These hospitals specifically catered for people with an intellectual handicap (Tennant 1996). It was not uncommon, however, for people with learning disabilities to be placed in psychiatric hospitals that catered primarily for people with mental health concerns.

When accused of stealing the running shoes Kevin had been isolated from his family and had few friends. On being arrested, he was in a vulnerable situation with little advocacy on his behalf from family or friends. There was no recognition by the court officials that a person's cognitive ability should be taken into account in understanding the consequences of alleged offences. Police records [Personal communication] state that the young man had difficulty explaining the situation, 
was incoherent and had difficulty expressing himself. The prevailing judicial system had no useful understanding of learning disability and comments such as these were not taken into consideration. The social model of disability (Oliver 1996) purports that societal institutions, including the judicial system, construct disability. Kevin's experience from being a young street-wise individual to one with many negative labels and consequent institutionalisation aligns strongly with this hypothesis.

Kevin's experience in the psychiatric institution illustrates the power of the individual model of disability (Oliver 1996) upon the lives of people who are so defined. The institution operated on the individual (medical) model, however, on the few occasions when Kevin required medical intervention, it was not forthcoming. For instance, on falling from a tree and injuring himself he received no treatment for these injuries. Furthermore, Kevin did not smoke on admission to the hospital but the weekly gift of tobacco was the start of a 30-year habit. A review of his medical records shows that the medical staff saw their role as one involving diagnosis and identification of difference rather than one of development and support.

Medical records also show that, in 1971 he was diagnosed as 'a high grade imbecile' and 'feeble-minded'. These records contain no plans for rehabilitation. There was no support in this environment to improve his quality of life - no education, training, personal management or employment skills. Kevin's day was filled with 'boring jobs', using skills he already had.

Even in the bleak environment of the hospital, this young man sought out friendships and opportunities to contribute. He endeavoured to develop work skills and involved himself in annual events like the hospital's Christmas play. He voluntarily strove to make valuable contributions even though these were not recognized or encouraged by the majority of hospital staff. There were, however, two staff members who, although entrenched in the systems and routines of the hospital environment, were prepared to reach out in their humanity, show empathy and acknowledge his intrinsic strengths.

After two years Kevin was discharged from hospital without a plan for community support. Prior to admission Kevin was a young man who had sought the openness, freedom and camaraderie of street culture. The hospital culture was in direct contrast with locked wards, strict routines, restricted activities and punitive environment. He found the experience of being back on the streets so overwhelming that he readmitted himself. Kevin's remand to a psychiatric hospital for observation where he was negatively labelled had further heightened his vulnerability to devaluation and poor treatment.

People with intellectual disability are at greater risk of exposure to a range of adversities than their non-disabled peers (Broberg et al 2009). Wolfensberger (1998a) postulates that a person with differences that are negatively perceived by society (such as having a learning disability or living on the streets), is at high risk of devaluation, adversity and poor treatment by the majority in that society. 
According to Wolfensberger when people are devalued they are subjected to a 'wounding process' described by Race (2003) as 'the bad things that typically get done to devalued people' (p.29). Hospital records vividly illustrate the wounding theory in practice with their long list of negative attributes that were assigned to Kevin after his admission.

Devaluation expresses itself at individual and collective levels in the form of assumptions (Wolfensberger 1998a) that can generate actions resulting in specific service models, policies and cultures. These actions are most likely to be detrimental to the interests and quality of life of the individual/s concerned (Schein 2010). Wolfensberger (1988b) refers to 'the assets' of people with learning disability. These assets are the individual skills and strengths of people with disabilities. Assets can be diminished and destroyed through degrading life circumstances thus inhibiting positive development and growth.

Kevin's story graphically illustrates the reality of social devaluation and wounding theory (Wolfensberger 1998a). Kevin was removed from his physical environment and subjected to isolation and segregation. In addition he was subjected to mass grouping, where people with learning disability, mental health problems and criminal records were grouped together. His natural free relationships were severed and increasingly replaced by more artificial, paid relationships. Little opportunity for paid work or any form of personal development while in this environment led to material poverty and impoverished experiences. The environment of the institution excluded Kevin from participating in activities that potentially give quality of life and support autonomy. The final wound Wolfensberger highlights is the receiving of additional labels - this was most evident in hospital records. A review of hospital records shows additional labels of 'sub-average intelligence, incapable of work' and 'holding no ambitions for his future'.

The experience of being admitted to the institution and the length of stay had a destructive effect on Kevin's competence to the extent that he 'voluntarily' readmitted himself after release. A young man who had lived on the streets now found himself daunted and frightened when he returned to the outside world. This illustrates the theory of learned dependency and low expectations (Wolfensberger 1998a), where people start fulfilling the dependent roles into which they are cast.

The intentional community Jerusalem, where Kevin went to live after hospital was on a remote stretch of the Wanganui River. The commune had been established in 1969 by James K. Baxter (Hemi), a famous New Zealand poet and was to be a place where Kevin would find a sense of belonging and contribution. With a bicultural, anti-materialist and spiritual philosophy, it had become a magnet for disillusioned and marginalised youth (Newton, 2009).

Kevin has vivid memories of the colourful and creative people who lived at Jerusalem. While living there he found acceptance and was able to fulfil a number of important roles to sustain and contribute to the community. Lemay (2005) proposes that experiencing 'a typical or indeed valued life might overcome much 
past adversity' (p.2) for disabled people. This was a busy and valued role through the recognition that:

although feeding everyone was not part of the Kaupapa [philosophy], long term resident Noddy (Kevin) put in a garden and if extra mouths showed up at mealtimes - as they almost invariably did - the available food would have to be reapportioned.

(Newton 2009, p. 158)

At the Top House there was an abundance of music, laughter, friendship and collaborative interaction. This provided Kevin with the much-desired sense of belonging and community spirit for which he was searching. At Hemi's tangi (funeral) Kevin was given the significant and valued role of pallbearer, signifying their close bond and Kevin's valued role in community life. Although a transient community, there was always room for everyone and a spirit of generosity and acceptance prevailed.

Hemi had a profound influence on Kevin, as did the Sisters of Compassion who also lived on the Wanganui River. The Sisters supported Kevin to learn to read, something that the school system had been quite unsuccessful in achieving. The non-judgemental environment and people who were caring and respectful impacted on his improved reading ability and creative writing.

The social architecture of Reef Point did not meet Kevin's needs, precipitating a move to a third intentional community. This was in Wellington and at the opposite end of the North Island. Here Kevin lived with two friends whom he had met while living in Jerusalem. This couple had a strong sense of social justice and opened their home to like-minded people. Kevin was then attracted to an intentional community in Auckland that was based on L'Arche philosophy (Vanier 1998) where members are encouraged to deepen their spiritual lives and where freedom of choice is respected. Kevin is currently still living in this community and has contributed to the Board of the community as a core member representative for two cycles.

Kevin's life story also illustrates his motivation to achieve. At Jerusalem he took an opportunity to be tutored by Sisters of Compassion, in his early twenties he went back to College to improve his literacy skills and in his mid-fifties he undertook a Certificate in Human Services at a tertiary institution. Kevin's story displays how he is driven by a sense of social justice. He has been elected twice to be a spokesperson on behalf of all people with disabilities and has worked as a consumer auditor, auditing and reviewing services for people with disabilities. He is a long-standing board member of two boards- one that supports adults with learning disability and one that supports people with mental health concerns.

Kevin's ability to problem solve, plan and make decisions has been an important factor in his ability to move on. After his experience in the institution Kevin knew he wanted to be somewhere 'he could belong' and his story demonstrates how he strove assiduously to make this happen. 
Intentional communities fostered caring positive environments and high expectations. This environment fostered a greater awareness of self, his place in the world and the contributions he can make. His role as a spokesperson gives credence to Swain and French's emerging affirmative model of disability (Swain and French 2000).

This model focuses on 'positive social identities... grounded in the benefits of life style and life experience of being impaired and disabled' (p.569). The affirmative model, while acknowledging disability, takes the position that 'disability is both identity and pride, through the celebration of difference' (Swain and French, 2008, p.2).

This story shows how Kevin has purposefully navigated community. He actively sought opportunities to contribute and find people with whom he could enter into reciprocal relationships. Kevin's identity is that of a valued citizen and contributor to society.

\section{Conclusion}

The telling of life-stories is a powerful way for people with disabilities to express and share their perspectives, experiences and journeys. It increases self-awareness and helps the story-teller process their experiences. Truly listening to life-stories is a powerful way for human and social service personnel to deepen understandings of what contributes a good life and to support people with learning disabilities to attain this. Kevin's story contains pertinent elements that contribute to the vision of a better future and the creation of the good life. His story embodies personal agency, hope, and a striving for a life of belonging and contribution. In Kevin's own words 'it took a long process to get over things'.

\section{References}

Atkinson, D. (2004) Research and empowerment: Involving with learning difficulties in oral and life history research. Disability and Society, 19, 691-702

Atkinson, D. (2005) Research as social work: Participatory research in learning disability. British Journal of Social Work, 35, 425-434

Broberg, M., Blacher, J. and Emerson E. (2009) Editorial for JIDR special issue on resilience and people with intellectual disabilities. Journal of Intellectual Disability Research, 53, 955-956 [doil0.1111/j.1365-2788.2009.001225.x

East, L., Jackson, D., O’Brien, L., and Peters, K. (2010) Storytelling: an approach that can help to develop resilience, Nurse Researcher, 17, 3, 17-25 
Kitzinger, C. (2004) Feminist approaches. in: C. Seale, G. Giampietro, J. Gubrium, D. Silverman (Eds.) Qualitative Research Practice. Sage: London (pp.125-140)

Leadbeater B., Dodgen D. and Solarz A. (2005) The resilience revolution: A paradigm shift for research and policy. In: Peters R.D., Leadbeater B. and McMahon R.J., eds. Resilience in children, families, and communities: linking context to practice and policy. New York: Kluwer, 47-63

Lemay, R. (2005) Resilience, the developmental model and hope. The Crucial Times, 34, 5-6

Masten, A. S. (2001) Ordinary magic: Resilience processes in development. American Psychologist, 56, 227-238

Meininger, H. (2006) Narrating, writing, reading: Lifestory work as an aid to (self) advocacy. British Journal of Learning Disabilities, 34, 181-188

Newton, J. (2009) The Double Rainbow: James K Baxter, Ngati Hau and the Jerusalem Commune. New Zealand, Victoria University Press

Oliver, M. (1996) Understanding Disability: From theory to practice. London, England, Macmillan.

Race, D. (2003) Selected Readings from Wolf Wolfensberger. New York: Routledge

Roberts, B. and Hamilton, C. (2010) Out of the darkness into the light: A lifestory from Ireland. British Journal of Learning Disabilities, 38, 127-132

Schein, E. (2010) Organizational Culture and Leadership. (4th ed.) San Francisco: Jossey-Bass

Sheldon, K.M. and King, L. (2001) Why positive psychology is necessary. American Psychologist, March, 216-217

Stanfield, R.B. (2000) The Art of Focussed Conversation. Gabriola Island, Canada: New Society Publishers

Swain, J. and French, S. (2000) Towards an Affirmation model of disability. Disability and Society, 15, 569-582

Swain, J. and French, S. (2008) Disability on Equal Terms. London: Sage

Tennant, M. (1996) Disability in New Zealand: An historical survey. New Zealand Journal of Disability Studies, 2, 3-33.

Vanier, J. (1998) Becoming Human. Toronto: House of Anansi Press

Wehmiller, P. (1992) When the walls come tumbling down. Harvard Educational Review, 62(3), 373-383

Wolfensberger, W. (1998a) A Brief Introduction to Social Role Valorization: A high-order concept for addressing the plight of societally devalued people, and for structuring human services (3rd ed.). Syracuse, NY, Syracuse University Training Institute for Human Service Planning, Leadership \& Change Agentry

Wolfensberger, W. (1998b) Common assets of mentally retarded people that are commonly not acknowledged. Mental Retardation, 26, 63-70 